\begin{tabular}{c|c|c}
\hline ISSN 2525-4812 (versão online) & Revista Terceira \\
$\begin{array}{c}\text { ISSN 2238-7641 (versão impressa) } \\
\text { http://www.revistaterceiramargem.com/ } \\
\text { index.php/terceiramargem/index }\end{array}$ & $\begin{array}{c}\text { Recebido em: 19/6/2019 } \\
\text { Aprovado em: } 30 / 2 / 2020\end{array}$ & $\begin{array}{c}\text { Margem Amazônia } \\
\text { Período de publicação: jul/dez, 2020 }\end{array}$ \\
\hline
\end{tabular}

Como citar o artigo:

ROCHA, S. A. Mercantilização da política de saneamento em Manaus. Revista Terceira Margem Amazônia, v. 6, n.15, p. 150-165, 2020. Doi: http://dx.doi.org/10.36882/2525-4812.2020v6i15p150-165.

\title{
MERCANTILIZAÇÃO DA POLÍTICA DE SANEAMENTO EM MANAUS
}

\author{
Sandoval Alves Rocha ${ }^{1}$
}

\begin{abstract}
Resumo: Este artigo é um dos resultados de uma pesquisa empírica realizada na cidade de Manaus, tendo em vista a aquisição do título de doutor. A partir da análise de documentos, entrevistas e tendo em mãos uma vasta bibliografia, busca-se vislumbrar o processo de expansão do capitalismo no território amazônico, tomando como base a privatização dos serviços de água e esgotamento sanitário. Riqueza natural de grandes proporções na Amazônia, a água torna-se objeto de cobiça de grandes empresas privadas que buscam ampliar os seus rendimentos. No entanto, se de um lado, a privatização dos serviços de água e esgoto em Manaus constitui estratégia de geração de lucros para estas empresas, de outro lado, a concessão privada ter sido marcada pela realização de serviços precários, principalmente nas periferias da cidade.
\end{abstract}

Palavras-chaves: saneamento básico, privatização, desempenho e periferias urbanas.

\begin{abstract}
This article is one of the results of empirical research realized in the city of Manaus for the purpose of acquiring the title of Doctor. Starting from the analysis of documents and interviews and having available a vast bibliography, it seeks to gain a glimpse of the process of the expansion of capitalism in the Amazon territory, based on the privatization of the services of water and the treatment of sewerage. As a natural richness of great proportions in the Amazon region, water has become the object of selfinterest of huge private companies which seek to enlarge their profits and earnings. However, if on the one hand the privatization of services of water and sewerage constitutes a strategy of generation of profits for these companies, on the other hand the private concession in Manaus has been marked by the precarious realization of services, principally in the urban peripheries
\end{abstract}

Key words: basic sanitation; privatization; realization; urban peripheries

${ }^{1}$ Doutor em Ciências Sociais pela Pontifícia Universidade Católica do Rio de Janeiro 


\section{INTRODUÇÃO}

A concepção do mercado como principal promotor das liberdades individuais e do bem-estar humano ganhou hegemonia na era da globalização tendo como guardiões a tríade FMI, Banco Mundial e OMC, associada aos interesses das principais potências mundiais (G-7), que a partir de uma perspectiva geopolítica, disputam pelo domínio dos demais Estados nacionais. Segundo Berta Becker (2009), esta disputa entre as potências mundiais, "não mais visa à apropriação direta dos territórios, mas sim o poder de influir na decisão dos Estados sobre o seu uso". Num cenário em que se verifica uma globalização crescente dos problemas ligados ao meio ambiente, a questão ambiental ganha relevância, recolocando a Amazônia como um dos elos estratégicos na disputa entre as nações pelo controle dos estoques de natureza.

Esta pesquisa corrobora a concepção de que as grandes empresas nacionais e internacionais, assim como os países mais ricos alimentam interesses nos recursos naturais concentrados nos territórios amazônicos. Recorrendo à técnica de observação participante, mediante a qual se pode vislumbrar presencialmente a realidade pesquisada e através da análise de documentos oficiais foi possível abordar com profundidade os desafios do saneamento básico em Manaus ao longo do período da privatização dos serviços de abastecimento de água e esgotamento sanitário, assim como caracterizar a gestão privada destes serviços essenciais.

Riqueza de difícil acesso em muitos países, mas abundante na Amazônia, a água, ao ser submetida à lógica do mercado, é transformada em objeto de compra e venda através do qual empresas de grande porte buscam gerar lucros e rendimentos. Da parte da empresa trata-se de um grande negócio, mas da parte da população de Manaus este empreendimento transforma o acesso à água em grande desafio a ser alcançado, principalmente para as populações economicamente mais vulneráveis, residentes nas periferias, ocupações e palafitas da cidade.

Este artigo se propõe a descrever a atuação das empresas de abastecimento de água e esgotamento sanitário em Manaus, no contexto da privatização destes serviços. Retrata também a atual situação da cidade que já conta com quase duas décadas de concessão privada. 


\section{O MERCADO SE APROPRIA DOS TERRITÓRIOS E DA NATUREZA}

Em épocas de tendências neoliberais, dilata-se a esfera da mercadoria, levando Becker a postular que o processo de mercantilização da natureza gera mercados reais que buscam ser institucionalizados, configurando formas de governabilidade global sobre o ambiente planetário mediante o estabelecimento de regimes ambientais globais e sistemas de regras e normas para regular as ações nacionais, visando o controle das decisões sobre os seus territórios. Deste modo, o processo de mercantilização avança sobre a Amazônia, incorporando o seu patrimônio territorial e atribuindo valor de troca ao ar, à vida e à água (BECKER, 2009). Com a instituição generalizada da propriedade privada, possibilitando a apropriação privada da natureza, o processo de mercantilização transforma a Amazônia em fronteira do capital natural.

Becker vislumbra a valoração contemporânea do "mercado da água" como resposta à limitada disponibilidade de água doce no planeta para responder ao forte crescimento do consumo global. A autora também assinala a mercantilização da água como forma de suprir déficits do recurso em diversas regiões. A bacia amazônica contém a mais extensa rede hidrológica do planeta, com um total de 6.925 .000 quilômetros quadrados. Abrange territórios de sete países sul-americanos, mas $63 \%$ estão localizados no Brasil. Tendo em vista essa abundância hídrica, de um lado, e a escassez em outras áreas do planeta, a autora entrevê o grande potencial da Amazônia para a exportação da água.

Neste cenário, os governos dos países em desenvolvimento são pressionados por organismos multilaterais e lobbies empresariais a adotarem políticas de privatização dos serviços públicos de saneamento básico como forma de reduzir os gastos públicos e ampliar a abrangência do acesso à água tratada e ao esgotamento sanitário, subordinando a provisão desses serviços à lógica dos interesses do mercado. Assim, o setor da água, convencionalmente dirigido e controlado pelo Estado, entra em sintonia com as forças de mercado globalizado e com os imperativos de uma economia privada e competitiva. As empresas de saneamento tornam-se parte de empresas globais, com base em locais diversos ou de conglomerados multisserviços, visando controlar o uso e a gestão da água nos territórios nacionais (BRITTO e REZENDE, 2017).

Por outro lado, existem nos níveis global, nacionais e locais iniciativas que defendem os serviços de água e esgoto como bens públicos ou sociais orientadas para o fortalecimento de capacidades locais, a promoção da cooperação e das parcerias públicas 
e público-comunitárias de orientação democrática capazes de facultar a defesa do bem comum (CASTRO, 2016). Assim, vislumbra-se o surgimento de diversos atores, fazendo do setor de saneamento uma arena de conflitos. Soraya Cortes e Luciana Lima (2012), ao estudarem as configurações contemporâneas das políticas públicas, identificam na interface entre Estado e Sociedade Civil a interação entre atores estatais, atores de mercado e atores sociais. Segundo estas autoras,

Os atores estatais e de mercado seriam compelidos a agir em ambientes regidos pelo poder e pelo dinheiro. Enquanto o mesmo não acontece com os atores sociais. Estes não visam tomar o poder do Estado ou organizar a produção, mas sim exercer influência por meio da participação em associações e movimentos democráticos (CORTES e LIMA, 2012, p. 39).

Diante da diversidade de agentes atuando nas políticas públicas, as pesquisadoras ainda esclarecem que os atores de mercado buscam controlar e administrar a produção, maximizando seus lucros no ambiente mercantil. Para elas, os decisores econômicos, por mais que discutam problemas como os impactos sociais ou ambientais de ações empresariais e decisões estatais, não podem se furtar aos imperativos da produtividade e do lucro. Suas ações seriam guiadas por tais imperativos.

No Brasil, a mercantilização da água recebeu um forte impulso a partir da década de 1990, nos governos de Collor de Melo e Fernando Henrique Cardoso. O primeiro criou o Programa de Modernização do Setor de Saneamento (PMSS), que previa a obtenção de recursos através do Banco Mundial, permitindo o avanço das diretrizes desta agência multilateral na formulação das novas políticas do setor. O segundo vetou financiamentos em saneamento para os órgãos públicos como forma de reduzir os gastos públicos. Além disso, FHC sancionou a Lei de Concessões e Permissões ( $\left.n^{\circ} 8.987 / 95\right)$, que possibilita a transferência da realização de serviços públicos para particulares. Estas medidas reforçaram a privatização dos setores de água no Brasil, permitindo que os grupos nacionais e transnacionais se lançassem à obtenção dos pontos estratégicos para a ampliação dos lucros e reprodução do capital. 


\section{A SAGA DA PRIVATIZAÇÃO DOS SERVIÇOS DE ÁGUA E ESGOTO EM MANAUS}

A privatização do saneamento básico em Manaus promoveu a mobilização de diversos atores do mercado da água, interferindo diretamente nos serviços de abastecimento de água e esgotamento sanitário como forma de ampliar os lucros e a rentabilidade do capital. A atratividade deste negócio foi percebida durante o processo de venda da antiga estatal Manaus Saneamento, subsidiária da Companhia de Saneamento do Amazonas (COSAMA), chamando a atenção de inúmeros interessados: o grupo inglês Thames Water, o consórcio ítalo-argentino formado pelo grupo Macri e a Civilia, os grupos franceses Lyonnaise des Eaux e Vivendi - este, aliado ao grupo brasileiro Andrade Gutierrez, e, o grupo norte-americano Azurix.

Em 29 de junho de 2000, depois de um polêmico e controverso processo de privatização, o grupo Lyonnaise des Eaux arrematou a empresa Manaus Saneamento por um preço de R\$ 193 milhões de reais, assumindo, na maior cidade da Amazônia, a exploração dos serviços de água e esgotamento sanitário. No entanto, além do grupo francês, durante o período de concessão privada, também atuaram os grupos brasileiros Solvi e Águas do Brasil. Atualmente, estes serviços são realizados pelo grupo Aegea Saneamento e Participações S.A.

\section{O GRUPO LYONNAISE DES EAUX}

O grupo Lyonnaise des Eaux, atualmente chamado de Suez S.A., constitui um bom exemplo para mostrar a internacionalização do mercado da água, que se transformou numa importante estratégia de acumulação de riqueza e reprodução capitalista. Isto confirma a reflexão de Maude Barlow e Tony Clarke (2003), quando eles afirmam que o mercantilismo, não somente da água, mas também de outras áreas da natureza e da própria vida, é uma característica distintiva da atual globalização conduzida por grandes corporações.

A Suez, juntamente com a Vivendi Universal, outra corporação francesa, são as duas maiores companhias distribuidoras de água do mundo. Elas controlam o monopólio de mais de $70 \%$ do mercado da água mundial (BARLOW e CLARKE, 2003). Com origens no século XIX, elas foram pioneiras na construção da indústria da água, aprendendo com o mercado e ampliando suas operações por meio de seus mercados 
domésticos. Segundo Julio Godoy (2003), do Consórcio Internacional de Investigação Jornalística, essas empresas, confortavelmente seguras em seu mercado doméstico, partiram nos anos 1980 para privatizar os serviços de água ao redor do mundo. Atualmente, a Suez controla serviços de água em 70 países nos cinco continentes e tem cerca de 58 milhões de clientes.

O grupo Suez S.A atuou em Manaus por meio da subsidiária DRMA Participações e Empreendimentos S.A. Sob a perspectiva da escassez de água doce no planeta, torna-se importante para os grandes conglomerados manter o controle sobre as regiões detentoras de grandes reservatórios hídricos. Para Cristiane Oliveira (2007), a expansão territorial das concessões em pontos de grande produção de água reflete a estratégia de valoração econômica por parte dos grupos privados transnacionais. Note-se que a posição geográfica de Manaus é privilegiada, pois está junto ao rio Negro, o principal afluente do rio Amazonas.

Segundo o modelo de concessão adotado para Manaus, a empresa ficou responsável pela administração e operação dos serviços, bem como pela manutenção e investimentos. A posse dos ativos, ou seja, da infraestrutura, continua sendo do Estado, por meio de suas instâncias de governo municipais, já que são estas que detém a titularidade dos serviços (CF 1988, Art. 30, Inciso V). Deste modo, o poder concedente, representado pelo governo municipal de Manaus, delegou a operação dos serviços por 30 anos (prorrogáveis por mais 15 anos), com a garantia de que a empresa pudesse obter o equilíbrio econômico e financeiro e com a segurança de haver ressarcimento de custos não amortizados, em caso de rescisão do contrato antes do prazo estipulado.

O diagnóstico técnico da Comissão Parlamentar de Inquérito (CPI de 2012), instalada na Câmara dos Vereadores de Manaus para investigar a situação dos serviços de água e esgoto na cidade, informa que poucos meses depois da concessão, em função da falta de investimentos por parte da Concessionária, o poder concedente aportou $\mathrm{R} \$$ 100 milhões de reais para realização das obras de ampliação do abastecimento de água na cidade. Ora, Oliveira (2007) destaca em estudo sobre a atuação do Grupo Suez em Manaus, que a possibilidade de obter financiamentos é um dos grandes pilares de estímulos aos grupos transnacionais do setor de saneamento básico.

A autora ressalta ainda que, em 2003, o Banco Nacional de Desenvolvimento Econômico e Social (BNDES) financiou um projeto no valor de $\mathrm{R}$ \$ 65,7 milhões de reais a ser investido na ampliação da cobertura do abastecimento de água em Manaus. Segundo esta pesquisadora, os financiamentos para investimentos representam aumentos 
significativos de lucros por parte da empresa, pois possibilitam a obtenção de grandes somas de dinheiro subsidiadas pelo Estado. Deste modo, a possibilidade de captação dos investimentos em saneamento básico aparece como uma grande vantagem para os grandes grupos econômicos.

Mesmo dispondo de todos estes recursos, o Relatório da "CPI da Água dos Amazonas", instalada em abril de 2005, revela que a atuação do Grupo Suez foi desastrosa, levando o abastecimento de água da cidade a uma situação calamitosa, visto que cerca de um terço da população (500 mil habitantes) estava totalmente sem água ou com o abastecimento precário. O mais grave era o fato de não haver nenhum plano ou projeto de solução do problema por parte da empresa ou na esfera dos poderes públicos.

Quanto ao esgotamento sanitário, a CPI de 2005 evidenciou o desrespeito sistemático do contrato de concessão, por parte do Grupo Suez, como consequência da falta de investimentos. Foi identificado que praticamente $100 \%$ das instalações relacionadas ao esgoto estavam paralisadas, causando uma situação de calamidade pública com gravíssimas consequências ambientais e sanitárias. Surtos de doenças de veiculação hídrica como dengue, hepatite e verminoses se proliferavam. Representante da Suez, a Concessionária Águas do Amazonas atendia somente um contingente de 30 mil pessoas e jogava os esgotos in natura nos igarapés, causando um prejuízo ambiental gigantesco.

Com isso, a comissão de inquérito depreendeu que a concessão privada era inviável, sugerindo a quebra do contrato e indicando vestígios sólidos da ocorrência do crime de prevaricação por parte do poder concedente. O Prefeito de plantão (Serafim Corrêa) ignorou as sugestões da CPI, alegando falta de recursos para pagar a milionária indenização, em caso de rescisão do contrato antes do término previsto. No entanto, em 2006, a multinacional se retira do negócio da água em Manaus, transferindo a concessão para o grupo Soluções para a Vida (Solví).

\section{O GRUPO SOLUÇÃO PARA A VIDA (SOLVÍ)}

A trajetória do Grupo Solví teve início em 1997, quando a Vega Engenharia Ambiental e a Relima juntaram-se para atuarem nos serviços de limpeza pública ${ }^{1}$. Ao longo dos anos, novas empresas foram sendo criadas ou adquiridas, tornando o Grupo

\footnotetext{
${ }^{1}$ Informações disponíveis em <http://www.solvi.com/vega/>, Acesso em: 10 mai. 2018.
} 
mais abrangente em diferentes unidades de negócio: engenharia, resíduos públicos, saneamento, resíduos industriais e produção de energia. Presente em mais de 250 cidades brasileiras e sul-americanas e com operações em mais de 130 municípios, o Grupo Solví possui mais de 26 milhões de clientes. Além de atuar no Brasil, a Solví também está presente no Peru, na Argentina e na Bolívia, explorando os serviços ligados aos resíduos públicos.

O Grupo Solví deu início a sua atuação em Manaus no ano de 2006, assumindo o contrato de concessão iniciado pela multinacional Suez. Com a gestão do abastecimento de água e esgotamento sanitário de Manaus, o grupo alimentava grandes expectativas em ampliar a sua intervenção no Norte do Brasil. A aquisição da concessionária Águas do Amazonas constituiu um fato relevante do ponto de vista da gestão e estratégia de negócio na empresa. Segundo relatório anual da empresa ${ }^{2}$, com a integração da concessionária Águas do Amazonas, o Grupo já entrava na cidade contabilizando um faturamento de R\$ 149 milhões de reais, obtendo um crescimento de 5\% em relação ao ano anterior.

Foram inúmeros os benefícios recebidos pelo Grupo, ao assumir os serviços de água e esgoto em Manaus. O primeiro deles se refere à própria repactuação do contrato de concessão, em janeiro de 2007. Sobre este acordo, o Professor Cardoso Filho ${ }^{3}$ elucida: “o que entendo por esta repactuação é um atestado de incompetência por parte do poder público, pois, como repactuar ou realiançar uma aliança que já foi quebrada logo nos primeiros meses de existência desta privatização?" (CPI 2012).

Outros benefícios auferidos pelo Grupo aparecem no Aditivo ao Contrato de Concessão de Prestação de Serviços Públicos de Abastecimento de Água e Esgotamento Sanitário do Município de Manaus (Janeiro de 2007). Neste documento, é estabelecido o valor máximo de multas pelas infrações cometidas; é formalizada a possibilidade de o poder concedente atuar com aportes financeiros na melhoria do sistema de água e esgoto; e, o mais agravante de tudo, a redução das metas e indicadores a serem alcançados pela concessionária.

Mesmo com inúmeros benefícios conferidos pelo Estado, o Grupo Solvi, ao longo de 6 anos de atuação, não desempenhou trabalho satisfatório, mantendo os serviços de água e esgotamento sanitário em situação de precariedade, principalmente nas zonas

\footnotetext{
${ }^{2}$ Informações disponíveis em: <http://www.solvi.com/wp-content/uploads/2015/03/relatorio-solvi-por2006.pdf>, Acesso em: 18 mai. 2018.

${ }^{3}$ O Professor Cardoso Filho, da Universidade Federal do Amazonas, coordenou a comissão técnica da CPI de 2012, encarregada de realizar a auditoria contábil do contrato de concessão.
} 
periféricas da cidade. ${ }^{4}$ Para se ter uma ideia da atuação do Grupo Solví, pode-se visualizar o elevado número de processos impetrados contra a concessionária Águas do Amazonas no Tribunal de Justiça do Estado, chegando à cifra de 2.433 ações somente entre os meses de janeiro e julho de 2012. Trata-se de processos de variados conteúdos relativos a infrações e ilegalidades cometidas pela Concessionária, inclusive descumprimentos de ordens judiciais.

Todas estas manifestações que deixam entrever a precariedade dos serviços prestados pelo Grupo Solví tem seu desfecho na instalação de uma Comissão de Inquérito com o objetivo de apurar responsabilidades pela crise de abastecimento de água na cidade de Manaus, tendo em vista que o acesso à água é direito fundamental, pois sem água não há vida (CPI de 2012).

A CPI de 2012 retoma parte dos inquéritos da CPI de 2005, analisa a coerência das investigações e medidas adotadas, confirmando o não cumprimento do contrato de concessão e o desequilíbrio contábil financeiro da empresa. Diante das evidências, o relatório técnico mostra a ocorrência de inúmeras situações que respaldavam juridicamente a rescisão do contrato de concessão já no ano de 2005, principalmente o descumprimento do princípio de eficiência da parte da Concessionária e a falta de investimento no sistema de saneamento básico.

Analisando os documentos e realizando pesquisas de campo pela cidade, a comissão técnica da CPI 2012 pôde comprovar a precariedade dos serviços prestados pela empresa. Dentre os aspectos que chamam atenção estão: a falta de zelo pelos equipamentos do sistema; a falta de plano para coibir as perdas de água; o descumprimento das metas contratuais de expansão do sistema; e, a política tarifária inadequada. A CPI chama atenção também para os grandes investimentos realizados pelo Estado durante o período de concessão ${ }^{5}$. A comissão constatou que,

\footnotetext{
O poder público investe, assume o encargo do financiamento e a concessionária opera e lucra. $\mathrm{O}$ equilíbrio econômico-financeiro fica garantido para o contrato e o usuário paga duas vezes pelo serviço: uma diretamente através da tarifa de água e/ou esgoto e outra através dos impostos que vão garantir o financiamento. A modernização e preparação para as demandas futuras vêm sendo realizadas quase que exclusivamente pelo setor público, cabendo à concessionária apenas a operação e o lucro da atividade (CPI 2012, p. 297).
}

\footnotetext{
${ }^{4}$ MINISTÉRIO PÚBLICO DO ESTADO DO AMAZONAS. Relatório final dos atos praticados pelo grupo de trabalho designados pela Portaria 210/2012. Manaus, 29 fev. 2012.

5 Até o ano de 2012, os investimentos do Estado já ultrapassavam R\$ 580 milhões de reais (Acritica. Manaus. 19 fev. 2012. Tema do Dia, p. A3)
} 
Esta conclusão a que chegaram as investigações da CPI demonstra o equívoco das políticas neoliberais que promovem a privatização do saneamento básico, especialmente nos países em desenvolvimento, sob o pretexto da maior eficiência do setor privado. Para tanto, passam a vislumbrar o saneamento como um negócio empresarial e a água como uma commodity, tratando o problema como uma atividade econômica. Prometem que este modelo estende a cobertura dos serviços, viabiliza os investimentos necessários e alivia os governos dos déficits orçamentários. Ao contrário, segundo Léo Heller, Sonaly Cristina Rezende e Pedro G. Barbosa Heller (2008), o modelo vem se mostrando incapaz de responder globalmente aos elevados déficits do setor, excluindo mais ainda a população pobre dos serviços e contribuindo mesmo para aprofundar desigualdades sociais.

Em plena realização da CPI 2012 a Solvi se retira da cidade, transferindo a gestão dos serviços de água e esgoto para o grupo empresarial Águas do Brasil

\section{O GRUPO ÁGUAS DO BRASIL}

O Grupo Águas do Brasil representa um dos maiores conglomerados brasileiros no setor de concessões privadas prestadoras de serviços de abastecimento de água, coleta e tratamento de esgotos. Fundado em 1998, o Grupo está presente em 15 municípios brasileiros, através de 14 concessionárias, distribuídas pelos estados do Rio de Janeiro, São Paulo, Minas Gerais e Amazonas, atendendo a uma população superior a 6 milhões de clientes.

Com a negociação, o Grupo Solví não se afastou totalmente de Manaus. Apenas vendeu 50,50\% das ações da concessionária Águas do Amazonas para o Grupo Águas do Brasil, transferindo-lhe o controle acionário da gestão dos serviços de água e esgoto da cidade. Assinando o Quarto Termo Aditivo ao Contrato de Concessão, o novo Grupo assumiu o controle dos serviços, alterando o nome da concessionária para Manaus Ambiental S.A e prometendo um investimento de $\mathrm{R} \$ 3,4$ bilhões de reais.

Entre as novas alterações do contrato, destacaram-se a ampliação do período de concessão de 30 para 45 anos (até 2045), o aumento do valor dos serviços de esgoto de $80 \%$ para $100 \%$ do valor da água consumida e novas mudanças nas metas são estabelecida, beneficiando a empresa: a cobertura de abastecimento de água de $98 \%$ até o ano de 2016 e implantação de $90 \%$ do tratamento de esgoto na cidade até 2040. Além disso, foi reforçada a promessa da implantação da tarifa social. Ao Grupo Águas do Brasil 
foram transferidas as obras concluídas do Programa Águas para Manaus (PROAMA), que custaram aos cofres públicos o montante de $\mathrm{R} \$ 365$ milhões de reais, numa tentativa de resolver o problema da falta de água nas zonas Norte e Leste da cidade. O Grupo se incumbiu somente de operar o sistema, mantê-lo e lucrar sobre o abastecimento de água nestas áreas.

Sem cumprir as metas contratuais, em fevereiro de 2018, o Grupo Águas do Brasil anunciou a venda das ações da concessionária Manaus Ambiental ao Grupo Aegea Saneamentos e Participações, transferindo-lhe a gestão dos serviços de abastecimento de água e esgotamento sanitário da cidade de Manaus. A negociação foi realizada em sigilo, surpreendendo toda a cidade, inclusive os poderes públicos ligados ao setor de saneamento (Agência Reguladora dos Serviços Concedidos e Câmara Municipal dos Vereadores). A iniciativa também surpreendeu o Ministério Público do Amazonas (MPAM), que entrou com ação judicial para investigar a transação.

O Grupo Aegea Saneamento e Participações responde um processado criminal movido pelo Ministério Público do Estado de São Paulo (MP-SP), em que os seus dirigentes respondem por organização criminosa, fraude em licitação, peculato e corrupção. No processo que tramita em São Paulo, o engenheiro Jorge Carlos Amin, executivo da Aegea, foi preso acusado de negociar o pagamento de propina. Em março de 2017, a Justiça bloqueou R \$ 18 milhões do grupo Aegea, alvo de investigação da forçatarefa da Operação Sevandija por suspeita de pagamentos de propina e fraude em licitação de obras do Departamento de Água e Esgoto (Daerp) de Ribeirão Preto (SP). ${ }^{6}$

O Grupo, que se encontra entre os 5 maiores do Brasil, atua em 48 cidades, em 11 estados do Brasil e atende aproximadamente 7,6 milhões de habitantes. Em Manaus, que é a terceira capital atendida pela empresa (Campo Grande/MS e Teresina/PI), o Grupo prevê o investimento de $\mathrm{R} \$ 880$ milhões de reais nos próximos 5 anos, atingir $80 \%$ de cobertura de esgoto até 2030, além de reduzir o desperdício e melhorar o abastecimento de água na capital. Neste interim, o nome da concessionária Manaus Ambiental foi alterado para Águas de Manaus.

Com a concessão dos serviços de água e esgoto em Manaus, a Aegea visa expandir sua atuação no mercado brasileiro, passando a ser a maior empresa privada do setor de

\footnotetext{
${ }^{6}$ EDITOR. Ministério Público vai investigar venda da Manaus Ambiental para a Aegea. Portal Acritica. 20 de junho de 2018. Disponível:< https://www.acritica.com/channels/manaus/news/minis terio-publicovai-investigar-venda-da-manaus-ambiental-paraagea?fbclid=IwAR3AckWY2D0dSs_z

5u9S8unYGeM7lw6b4PeDdrzQmJ2kplrnQTfPtFzpFRs>, Acesso em: 12 de março de 2019.
} 
saneamento básico brasileiro. Esta negociação constitui uma importante estratégia para consolidar a presença da companhia na região norte do Brasil, onde já atende em municípios dos estados de Rondônia e Pará.

O Grupo empresarial possui $24 \%$ do mercado privado do saneamento brasileiro, sendo que um dos trunfos da companhia está na composição acionária, formada por instituições de peso. A Aegea é controlada pela Equipav, grupo que detém participação em vários setores, como açúcar e álcool, mineração, engenharia e concessões de infraestrutura. O diferencial, no entanto, está na participação do fundo soberano de Cingapura GIC e do Internacional Finance Corporation (IFC), do Banco Mundial.

\section{OS DESAFIOS DOS SERVIÇOS DE ÁGUA E ESGOTO EM MANAUS}

Os últimos índices do Sistema Nacional de Informação sobre o Saneamento Básico (SNIS/2017), ao divulgar os dados nacionais sobre o abastecimento de água e esgotos, revela a situação de Manaus, mostrando o seu desempenho em comparação com as outras cidades brasileiras. O quadro abaixo expõe a cobertura dos serviços de água e esgoto nas capitais da Amazônia, indicando a situação da capital amazonense:

Tabela 1: O Saneamento nas capitais da região norte em 2017

\begin{tabular}{|c|c|c|c|c|c|}
\hline \multicolumn{1}{|c|}{ MUNICÍPIO } & RANKING & $\begin{array}{c}\text { ATEND. } \\
\text { DE ÁGUA }\end{array}$ & $\begin{array}{c}\text { ATEND. } \\
\text { ESGOTO }\end{array}$ & $\begin{array}{c}\text { PERDA NA } \\
\text { DISTRIBUIÇÃO }\end{array}$ & $\begin{array}{c}\text { MÉDIA } \\
\text { TARIFA }\end{array}$ \\
\hline BRASIL & - & $83,40 \%$ & $52,40 \%$ & 38,3 & $\mathrm{R} \$ 3,63 \mathrm{~m}^{3}$ \\
\hline NORTE & - & $57,30 \%$ & $10,20 \%$ & 55,1 & $\mathrm{R} \$ 3,35 \mathrm{~m}^{3}$ \\
\hline PALMAS/TO & $23^{\circ}$ & $97,43 \%$ & $83,55 \%$ & $34,23 \%$ & $\mathrm{R} \$ 5,10 \mathrm{~m}^{3}$ \\
\hline B. VISTA/RR & $45^{\circ}$ & $97,73 \%$ & $62,53 \%$ & $69,33 \%$ & $\mathrm{R} \$ 2,94 \mathrm{~m}^{3}$ \\
\hline BELÉM/PA & $90^{\circ}$ & $71,27 \%$ & $12,99 \%$ & $36,42 \%$ & $\mathrm{R} \$ 2,62 \mathrm{~m}^{3}$ \\
\hline R. BRANCO/AC & $93^{\circ}$ & $54,93 \%$ & $21,65 \%$ & $58,70 \%$ & $\mathrm{R} \$ 2,20 \mathrm{~m}^{3}$ \\
\hline MACAPÁ/AP & $96^{\circ}$ & $41,50 \%$ & $10,17 \%$ & $62,15 \%$ & $\mathrm{R} \$ 2,73 \mathrm{~m}^{3}$ \\
\hline MANAUS/AM & $98^{\circ}$ & $89,26 \%$ & $12,25 \%$ & $74,62 \%$ & $\mathrm{R} \$ 5,63 \mathrm{~m}^{3}$ \\
\hline P. VELHO/RO & $100^{\circ}$ & $31,78 \%$ & $4,58 \%$ & $77,11 \%$ & $\mathrm{R} \$ 4,66 \mathrm{~m}^{3}$ \\
\hline
\end{tabular}

Fonte: SNIS-2017

Aparecendo na $98^{\mathrm{a}}$ posição, Manaus ocupa a $3^{\mathrm{a}}$ pior posição no ranking das 100 maiores cidades brasileiras naquilo que se refere aos serviços de abastecimento de água e esgotamento sanitário. Levando em consideração as sedes dos estados brasileiros, o saneamento realizado em Manaus supera somente Porto Velho, a capital do Estado de Rondônia, sendo pior que todas as outras capitais. Nesse sentido, a tabela mostra que a 
cobertura de água da cidade $(89,26 \%)$ supera a média nacional $(83,40 \%)$, mas o índice de atendimento de esgoto $(12,25 \%)$ indica que quase $90 \%$ da cidade não possui este serviço, sinalizando o baixo desempenho da concessão.

No referente à cobertura de água, é necessário destacar a diferença entre o índice que mostra a disponibilidade de rede urbana e o indicador que exibe o percentual de ligações residenciais, quando o consumidor tem efetivamente acesso à água. Se o primeiro índice apresenta $89,26 \%$ de cobertura, o segundo corresponde somente a $64 \%$ da população. ${ }^{7}$ Esta informação sugere que o acesso universal à água está muito mais distante do que aquilo que a empresa informa através dos dados fornecidos ao SNIS. Diante desta realidade, é possível afirmar que a gestão do serviço de abastecimento em Manaus se encaminha para uma "universalização maquiada", onde há a disponibilidade de rede, mas não se realiza o acesso efetivo ao serviço.

Importa averiguar, mais de perto, o desempenho do sistema de esgotamento sanitário, considerado um dos principais motivos da privatização em Manaus. Atualmente, não existe coleta de esgoto na maior parte da cidade, sendo os resíduos lançados in natura nos igarapés, córregos e rios, comprometendo inexoravelmente a qualidade dos corpos hídricos. Assim, relega-se ao segundo plano o investimento no esgotamento sanitário, causando prejuízo à saúde pública e do meio ambiente.

A cobrança da tarifa de esgotamento sanitário realizada pela concessionária corresponde ao percentual de $100 \%$ do valor cobrado pela água consumida. Este valor vem sendo questionado pela população, organizações da sociedade civil e órgãos de defesa do consumidor, no entanto, o mais surpreendente é o fato de essa tarifa ser muitas vezes cobrada até nas regiões da cidade onde o serviço não é realizado. ${ }^{8}$ Trata-se das “cobranças indevidas", realizadas pela concessionária como estratégia de ampliação de lucros, aguçando ainda mais o processo de espoliação urbana.

O indicador que se refere às perdas na distribuição de água apresenta o percentual de $74,62 \%$, mostrando a necessidade do investimento por parte da concessionária, em ações voltadas para redução e controle de perdas no sistema de distribuição. A concessionária tem comumente justificado a falta de investimento usando o argumento do desiquilíbrio financeiro da empresa, mas este argumento não explica o

\footnotetext{
${ }^{7}$ O percentual de $64 \%$ de ligações residenciais ao sistema de abastecimento só foi revelado em Audiência Pública na Defensoria Pública do Estado do Amazonas, ocorrida em 28 de setembro de 2017. Informação disponível no Portal da Defensoria Pública do Estado do Amazonas, em 18 Maio. 2018.

${ }^{8}$ Defensoria Pública tomará série de medidas contra a cobrança indevida de tarifa de tratamento de esgoto. Disponível no Portal da Defensoria Pública do Estado do Amazonas, em 18 Maio. 2018.
} 
descumprimento das metas, pois a empresa tem aumentado progressivamente os seus lucros ao longo da concessão.

A população tem comumente demonstrado insatisfação com respeito ao elevado preço das tarifas cobradas pela empresa. Como se observa na tabela acima, a concessionária cobra a tarifa mais cara da região amazônica $\left(\mathrm{R} \$ 5,63 / \mathrm{m}^{3}\right)$. Este aspecto constitui uma questão bastante preocupante se considerarmos os altos índices de pobreza e depressão da renda no Brasil contemporâneo. Essa realidade revela a inviabilidade social da perspectiva economicista empregada na gestão da água, que primando pelo retorno dos investimentos realizados, impede as populações mais vulneráveis de usufruir de um bem essencial para sobrevivência.

\section{CONSIDERAÇÕES FINAIS}

Neste artigo verificou-se a mobilização dos atores do mercado, buscando avançar sobre o território Amazônico, violando leis em nome do lucro. Esta mobilização ocorre em Manaus à medida que as empresas do setor de saneamento se apropriam dos serviços de abastecimento hídrico e esgotamento sanitário, impondo seu controle sobre as águas e promovendo a mercantilização da natureza.

A privatização dos serviços de abastecimento de água e esgotamento sanitário na cidade de Manaus, no ano 2000, representa uma das formas pelas quais o capitalismo se expande, apropriando-se da Amazônia e de seus recursos naturais. A gestão privada da água em Manaus é evidenciada como estratégia de controle sobre o território, submetendo a água às leis do mercado global, transformando-a em objeto de compra e venda a partir da atuação das empresas do setor de saneamento básico (Lyonnaise des Eaux, Grupo Solvi, Grupo Águas do Brasil e Aegea Saneamento). Estas empresas negociam entre si o controle da concessão, encontrando no mercado consumidor manauense um espaço privilegiado de capitalização e geração de lucros, tudo com o apoio do Estado, que proporciona facilidades e vantagens.

Ao longo desta exposição é evidenciada a parceria entre as concessionárias e o poder concedente em prejuízo do cumprimento das cláusulas do contrato de concessão dos serviços de água e esgoto, prorrogando o sofrimento de grande parte da população, que sobrevive sem o acesso adequado aos sistemas de abastecimento e esgotamento sanitário. Mesmo acessando a generosos investimentos públicos, as empresas não alcançam as metas de cobertura dos serviços, ainda que estas tenham sido reduzidas pelos 
Aditivos ao contrato de concessão ao longo do período de privatização. Na contramão das duas CPIs que sugeriram a quebra do contrato, a privatização da água e do saneamento se consolida na capital amazonense, logrando renovar a concessão e contribuindo para o avanço do capital sobre as águas da Amazônia.

A gestão privada dos serviços de água e esgoto em Manaus oferece serviços precários, revelando uma forte incoerência com o discurso da privatização, que promete eficiência e qualidade. A ineficiência dos serviços, no entanto, é percebida com mais evidência nas periferias da cidade. É possível afirmar, portanto, que o avanço do mercado sobre o território amazônico e sobre os estoques de natureza visa em primeiro lugar a geração de lucros para as grandes empresas em detrimento da satisfação das necessidades básicas das comunidades mais pobres.

Os índices de desempenho dos serviços de água e esgoto ao longo de todo o período de privatização têm colocado Manaus entre as piores grandes cidades do Brasil. Isso entra em choque direto com os índices de produção de riqueza, que a coloca entre as dez mais ricas, indicando, não somente que a riqueza produzida é concentrada nas mãos de poucos, mas também sinalizando que o modelo de desenvolvimento capitaneado pela atuação predatória de grandes empresas, gera uma expressiva classe de trabalhadores explorados e empobrecidos, sem saneamento básico e outros serviços essenciais para a vida.

Cooptada pela lógica do mercado, a política pública de saneamento em Manaus não visa universalizar os serviços, mas a atender aos setores sociais que podem responder às expectativas de lucro das empresas. Além do serviço de abastecimento de água, ausente em vários pontos da cidade e precário em outros, o desempenho serviço de esgotamento sanitário representa um notório sinal do modelo de gestão segregador e promotor de desigualdades implantado em Manaus.

\section{REFERÊNCIAS}

BARLOW, Maude; CLARKE, Tony. Ouro Azul. Como as grandes corporações estão se apoderando da água doce do nosso planeta. São Paulo: M.Book do Brasil Editora Ltda, 2003.

BECKER, Berta K. Amazônia. Geopolítica na virada do III milénio. Rio de Janeiro: Garamond, 2009.

BRITTO, Ana Lucia; REZENDE, Solany Cristina. A política pública para os serviços urbanos de abastecimento de água e esgotamento sanitário no Brasil: financeirização, 
mercantilização e perspectivas de resistência. Cad. Metrópoles. São Paulo, v. 19, no 39, pp. 557 - 581, maio/ago. 2017.

CÂMARA MUNICIPAL DE MANAUS. Relatório CPI da Água. Comissão Parlamentar de Inquérito. Manaus, Abril de 2012, 353p.

CÂMARA MUNICIPAL DE MANAUS. Relatório da CPI das Águas do Amazonas. Diretoria Legislativa. Manaus, 17 de agosto de 2005, 38p.

CASTRO, José Esteban. Água e Democracia na América Latina. Campina Grande: EDUEPB (Editora da Universidade Estadual da Paraíba), 2016.

CORTES, Soraya V; LIMA, Luciana L. A contribuição da sociologia para a análise de políticas públicas. Lua Nova, São Paulo, nº 87, 2012, p. 32 - 62.

GODOY, Julio. Water and Power: The French connection. Consórcio Internacional de Investigação Jornalística. 04 fev. 2003. Disponível em < https://www.icij.org/investigations/waterbarons/water-and-power-french-connection/> Acesso em: 05 mai. 2018.

HELLER, Léo; REZENDE, Sonaly Cristina; HELLER, Pedro G. Barbosa. Os desafios da universalização do saneamento básico no Brasil. In: BARBOSA, Francisco. (Org.). Ângulos da água: desafios da integração. Belo Horizonte: Editora UFMG, 2008.

MINISTÉRIO PÚBLICO DO ESTADO DO AMAZONAS (PROCURADORIA GERAL DE JUSTIÇA). Relatório Final dos Atos Praticados pelo Grupo de Trabalho Designado pela Portaria 210/2012. Manaus, 29 de fevereiro de 2012.

OLIVEIRA, Cristiane F. Água e Saneamento Básico. A atuação do Grupo Suez em Limeira e Manaus. Tese de Doutorado, Universidade de São Paulo, Faculdade de Filosofia, Letras e Ciências Humanas, Departamento de Geografia, 2007.

PREFEITURA MUNICIPAL DE MANAUS. Quarto Termo Aditivo ao Contrato de Concessão de Prestação dos Serviços de Saneamento Básico no Município de Manaus. Manaus, 17 de maio de 2012.

PREFEITURA MUNICIPAL DE MANAUS. Termo Aditivo ao Contrato de Concessão de Prestação de Serviços Públicos de Abastecimento de Água e Esgotamento Sanitário do Município de Manaus. Manaus, 10 jan. 2007 